\begin{tabular}{lll}
\hline Jij & Journal of Translation and Language Studies & J Trans \& Lang Stud \\
jtls.sabapub.com & $1(2020)$ \\
& & $1(1): 94-107$ \\
\hline
\end{tabular}

\title{
Exploring negation in Awing
}

\author{
Cyrine NYOMY ${ }^{1, *}$ \\ ${ }^{I}$ University of Yaounde I, Cameroon
}

Received: 05.10.2020 • Accepted/Published Online: 15.11.2020 • $\quad$ Final Version: 15.11.2020

\begin{abstract}
Negation is a universal category and languages differ in many respects in the way they express the latter (see Klima 1964). In this regards, some languages express sentential negation (a subcategorization of negation) with one marker (Dutch, German, English, etc.) while others like French uses two markers. Alongside markers used to express sentential negation, other items, among which Negative Polarity Items, mark negation and tight a particular element within its domain. In this paper, I aim at providing a picture of the expression of negation in Awing (a Bantu Grassfield langue of the Ngemba Group spoken in the North West region of Cameroon). Accordingly, sentential negation is expressed with two discontinuous markers kě...pô. One fact important to the presence of this negative marker is the movement of postverbal elements to a preverbal position turning the SVO structure in non-negative clause to an SOV pattern in negative clauses. In addition, the study describes other negative elements and negation subcategories. In last, the study of negative concord reveals that Awing belongs to the group of Strict Negative Concord (SNC) languages in which n-words must co-occur with negative marker to yield negation.
\end{abstract}

Keywords: negation, negative marker, negative concord, negative polarity item, sentential negation

\section{Introduction}

It is not altogether unfitting for a study on negation to begin with a negative statement. This is amazing, Klima's (1964) introductory sentence which, independently of any comment, is so clear revealing. It is so revealing because some properties of the grammar of individual languages or of UG do not simply lies in the midst of syntactic structures. This is to say, following Zanuttini (2001) there is no language in the world that does not express negation, at least sentential negation. Thus, negation is a characteristic of UG and the parametric variation observed in its expression is relatively permitted by idiosyncrasy properties of individual languages. Thus, there exists an abundant literature on negation studies cross linguistically dating back to Jespersen (1917). In the same lines, recent scholarly works devoted important materials in this domain (see Zeijlstra 2004, Giannakidou 1997, 1999 Zanuttini 1997, Haegeman 1995, among others). Such studies clearly demonstrate that negation and its expression occupy a central position in the description of languages. In the same of spirit of previous studies, this paper is devoted to the exploration of negation in Awing. Therefore, my main objective is to describe as exhaustively as possible items that

\footnotetext{
* Corresponding Author: cyrinenyomy@yahoo.com
} 
negate constituents of clauses. In this perspective, I will primarily talk of negative markers (NMs) and negative polarity items (NPIs) among which negative adverbs, negative quantifiers and $\mathrm{N}$-words. I will also present other aspects related to negation like sentential and negative concord, the imperative, among others. Let's begin with NMs.

\section{Expressing negation in Awing}

In this section

48521743,n, I will address negative markers and NPIs.

\subsection{2}

There exists a clear different between negative markers (NMs) and other negative items. Accordingly, Corbin and Tovena (2003) define NM as any expression or word that is present in a finite sentence and that is not an argument of the finite verb which presence imposes a negative representation of the sentence at the semantics. In addition, Zeijlstra (2004) indicates that NMs are items that are used to express sentential negation. Following these clarifications, Awing displays a rich range of NMs whose use is rigidly constraint by sentence mood. Consider the following examples.

1. Fochi a $g_{i} n^{3} \leftrightarrow$ wa'lo

Fochi SM P0-go school

'Fochi went to school'

2.

a. Fochi a $k \S \leftrightarrow$ wa'lə $g^{\prime} i^{3}$ pô

Fochi SM neg school P0-go neg

'Fochi did'nt go to school'

b. Fochi a m¥ ngi $n^{3} \leftrightarrow$ wa’lə

Fochi SM neg P0-go school

'Fochi did'nt go to school'

c. Fochi a chí' $\leftrightarrow$ wa'lə $\mathrm{gh}_{i} \mathrm{n}^{3}$ pô, gho fít $\angle \mathrm{m} \angle$

Fochi SM neg school P0-go neg 2sg tell 1sg-Obj

'If Fochi did'nt go to school, tell me'

d. $K_{\circ \jmath g h} n^{3} \leftrightarrow$ wa'lə

neg P0-go school

'Don't go to school'

By direct observation, (1) is distinct to (2) due to the fact negation is present in (2) and absent in (1). Taking (2) to be the concern of the focus, (i) it is clear that negation is express by four occurrences: $k \S$...pô in (2a), m¥ in (2b), chí'...pô in (2c) and ko in (2d). (ii) there can observe that there are structures where negation is expressed by a two items ( $2 \mathrm{a}$ and $2 \mathrm{c}$ ) or 
by a bipartite marker in the sense of Bell (2004) and others in which negation is marked by a single item ( $2 \mathrm{~b}$ and $2 \mathrm{~d}$ ). (iii), examples in (2) contrast with three sentence mood, the indicative in (2a-b), the conditional in (2c) and the imperative in (2d). From (2), the picture of negation via NMs is quiet indicative. Another issue that relates to the insertion of NMs in data like (2) concerns the structure of the sentence. It can be noticed that in (2a) and (2c) the object of the verb has moved across the latter. In other words, the DP $\leftrightarrow$ wa'lo 'school' has been displaced from its original position to the left of the verb $\mathrm{gh}_{\mathrm{i}} \mathrm{n}^{3}$ ' $\mathrm{go}$ '. In contrast, this displacement is not possible in (2b) and (2d), the postverbal object does not shift to the left of the verb. Questioning this phenomenon, what characterizes the difference observable in the pair $(2 \mathrm{a} / 2 \mathrm{c})$ vs. $(2 \mathrm{~b} / 2 \mathrm{~d})$ ? Why there is object movement in one case and not in other? These are questions that merit a particular attention but for moment, the intention is strictly descriptive and theoretical practice goes beyond the scope of this paper.

In addition to the contrast that exists in structure, the interpretation of sentences in (2) slightly differ regarding the negative marker. (2a/2c) are typical negative constructions since they share the same properties: object displacement and the bipartite nature of the negative marker, $k \S \ldots$ pô in (2a) and chí'...pô in (2c). Rather, in other examples (2b/2d), negation is marked by a single item and does imply object movement. I will refer to this polarity as strict vs. non-strict negative marker. My interpretation holds that only $\mathrm{k} \S$...pô in (2a) and chí'...pô in (2c) have strict negative reading in opposition to $m ¥$ in (2b) and ko in (2d) which have a non-strict negative semantics. Now, compare (3) to (2).

3.

a. *Fochi k§ a ↔wa'lə pô $\mathrm{gh}_{\mathrm{in}} \mathrm{n}^{3}$

Fochi neg SM school neg P0-go

'Fochi did'nt go to school'

b. *Fochi a- $m ¥ \leftrightarrow$ wa'lo $n g_{i} n^{3}$

Fochi SM neg school P0-go

'Fochi did'nt go to school'

c. *Fochi a- chí' $\leftrightarrow$ wa'lə $\operatorname{gh}^{\prime} n^{3}$, gho fít $\angle m \angle$ pô

Fochi SM neg school P0-go 2sgtell 1sg-Obj neg

'If Fochi did'nt go to school, tell me'

d. $\left.{ }^{*} \mathrm{~K}\right\lrcorner \mathrm{gh}_{i} \mathrm{n}^{3} \leftrightarrow$ wa'lə pô

neg P0-go school neg

'Don't go to school'

All sentence in (3) are ungrammatical for at least two reasons: (i) the position of the negative marker, (ii) the position of objects in bipartite negative constructions and (iii) the insertion of a second NM in the imperative clause. Deriving some conclusions based on (2) and (3), the following are worth of interest: the position of NMs is rigid, that object shift in structures like $(2 \mathrm{a} / 2 \mathrm{c})$ is not optional and finally that the imperative is a monopartite negative 
structure with the negative marker always clause initial. In the next section, let us look at NPIs.

\section{Negative Polarity Items}

This class covers a good number of items that belong to different lexical categories. It covers negative adverbs, negative quantifiers and negative words (n-words) (see Klima 1964, Zanuttini 1997, Giannakidou 1997, 1999, Zeijlstra 2004, among others). Giannakidou (1999:367) defines a polarity item $\alpha$ as (i) an expression whose distribution is limited by sensitivity of some semantic property of $\beta$ of the context of occurrence and (ii) $\beta$ is (non) veridical. Thus, a polarity item (PI, henceforth) is a lexical or functional item that can only appear in a specific affective environment associated with a specific feature or polarity. If the feature is positive, we talk of a positive polarity item (henceforth, PPI). But if the polarity is negative, then there is negative polarity item (NPI, henceforth). In this work, I will focus on three typical NPIs whose distribution follows in total the definition provided above. Let us begin with the polarity la' $\leftarrow$.

\section{Negative adverbs}

Consider the examples below

4.

a. $\mathrm{Ma} \leftrightarrow \mathrm{la}^{\prime} \leftarrow \mathrm{ko \leftrightarrow} \leftarrow$ ghô $\mathrm{t} \leftarrow$ mbí $\mathrm{m}^{1} \leftarrow<\mathrm{y}^{3}$

I ever love you untill world finish it

'I will ever love you till the end of time'

b. $\mathrm{Ma} \leftrightarrow \mathrm{k} \S$ ghô la' $\leftarrow$ ko↔ $\leftrightarrow$ pô $\mathrm{t} \leftarrow$ mbí $\quad \mathrm{m}^{1} \leftarrow \quad \leftarrow \mathrm{y}^{3}$

I neg you never love neg until world finish $3 \mathrm{sg}$-Obj

'I will never love you till the end of time'

5.

a. Mamoh a $n \leftarrow \operatorname{mbím}^{3}{ }^{3} \mathrm{y}^{3} \quad \mathrm{ng}^{3} \mathrm{a} \quad \mathrm{k} \S \mathrm{m} \leftarrow$ teen $^{3} \mathrm{la} \mathrm{a}^{\prime} \leftarrow$ gh $\mathrm{Ÿ} \leftarrow$ pô

Mamoh SM P3 accept 3sg-Obj that she neg market never go neg

'Mamoh denied that she will ever go to the market'

b. Mamoh a $\mathrm{n} \leftarrow$ nda' $\leftarrow$ nk $\Leftrightarrow \leftarrow{ }^{3} \mathrm{y}^{3} \mathrm{ng}^{3} \mathrm{a} \quad \mathrm{k} \S \mathrm{m} \leftarrow \operatorname{teen}^{3} \mathrm{la} \mathrm{a}^{\prime} \leftarrow$ ghŸn $\leftarrow$ pô

Mamoh SM P3 ever deny Prn that she neg market never go neg

'Mamoh ever denied that she will never go to the market'

6.

a. Ko $1 \mathrm{a}^{\prime} \leftarrow \mathrm{gh} \varnothing 5 \mathrm{n}^{3} \quad{ }^{3} \mathrm{~W}^{3}$

neg never go there

'Never go there/ don't ever go there'

b. $\quad$ Mbo $(\mathrm{Ma} \leftrightarrow)$ ndá' $\leftarrow \mathrm{k} \S{ }^{3} \mathrm{~W}^{3}$ ghØ̋ n pô

Mod 1sg-Subj never neg there go neg

'I will never go there'

7. 
a. $* \mathrm{Ma} \leftrightarrow \mathrm{la} \mathrm{a}^{\prime} \leftarrow \mathrm{ko \leftrightarrow} \leftarrow$ ghô $\mathrm{t} \leftarrow$ mbí $\mathrm{m}^{1} \leftarrow<\mathrm{y}^{3}$

I never love you untill world finish it

'I will never love you till the end of time'

b. $* 1 \mathrm{a} * \mathrm{gh} \not \mathrm{n}^{3} \quad{ }^{3} \mathrm{~W}^{3}$

never go there

'Never go there/ don't ever go there'

Looking at the behaviour of the polarity la' $\leftarrow$ in (4), (5) and (6), it is obvious and necessary to add to Giannakidou's (1999) definition of a polarity item that the interpretation of the latter (perceiving Awing situation) is limited by context sensitivity. This is the reason at first the PI la' $\leftarrow$ cannot be glossed because only the context determine whether it is a PPI or an NPI. $\mathrm{La}^{\prime} \leftarrow$ will receive negative reading never if and only if it shows up in sentence where there $\mathrm{NM}$ as it is the case in (4b), (5b) and (6). On the other hand, if the context is not negative, that is if there is no NM, la' $\leftarrow$ is interpreted as positive as demonstrated by (4a) and ( $5 b)$. Intriguing is also the fact it seems that the PI la' $\leftarrow$ has two orthographies. The phonological difference that shows up strictly depends on the context where the PI appears. When it is preceded by an item with nasal features, the latter are spread to the PI and it is as nda' $\leftarrow$. This is illustrated in (5b) and (6c) where la' $\leftarrow$ is preceded respectively by the $\mathrm{P} 3$ tense marker $\mathrm{n} \leftarrow$ and the $1 \mathrm{sg}$ subject pronoun ma $\leftrightarrow$. If this condition is not met, the PI is spelt as la' $\leftarrow$ as in other examples. Keep in mind that the PI la' $\leftarrow$ cannot type a clause as negative on its own (see 7). It must be in combination with a NM. Let us proceed with another NPI.

Another NPI which marks negation is ${ }^{3}$ ' $\leftarrow$ Ingá 'no'. It usually occur in yes-no context.

8.

a. ywun $\angle \mathrm{w}^{3}$ a pé’ ${ }^{3}$ ngì?

Person Dem SM P2 came

'Did that man come?'

b. $\quad{ }^{\prime} ' \leftarrow \operatorname{lngá~}($ a k§ yí pô $)$

No (he did not come)

It can be used a fragment answer of precedes a sentence with a negative content. This NPI functions similarly as ká. Take for consideration data below.

9.

a. Pengy§ $\mathrm{p}^{3} \mathrm{p} \ddot{\mathrm{Y}} \mathrm{p}^{3} \quad$ (po)- pé $^{3} \quad$ ngì?

women two Dem SM P2 came

'Did those two women come?'

b. ká *(pó k§ yí pô)

None *(they did not come) 
Similarly, ${ }^{3}$ ' $\leftarrow$ Ingá 'no' and ká 'none' can stand as fragment answers preceding question in yes-no context but while ${ }^{3}$ ' $\leftarrow$ Ingá 'no' can be followed by a clause, ká 'none' does not have this specificity. I will return to the properties of ká 'none' when I will talk of negative quantifiers. This section has addressed some basic adverbs that express negation in Awing though not in the way that NMs do. In the next section, I will provide a description of negative quantifiers.

\section{Negative quantifiers}

Negative quantifiers (negQuan) is used to label words that, in addition to introduce negative semantics, also a particular variables in the clause. Some examples of these words are the English nothing, the Dutch niets (Zeijlstra 2004). In those languages, negative quantifiers are sufficient to generate negative reading that is they do not need to combine with negative. But this properties is common to negative quantifiers in every language. Morphologically, a negative quantifier is an association of the negative adverb no (in English for instance) and a noun like thing to derive nothing or nobody. Awing does have these items and their morphology seems similar to that of English and Dutch in the sense that they also derive from combination of two roots ká 'none' and a variable like ajúm ${ }^{3}$ 'thing', ywun $\leftarrow$ 'body'. Consider what follows below:

10.

a. Mamoh a pé’3 k§ ká ajúm³ z $\square$ pô

Mamoh SM P2 neg nothing see neg

'Mamoh did not see anything'

b. Ká ajúm à $\mathrm{n} \leftarrow \mathrm{k} \S \mathrm{m} \angle \mathrm{m} \mathrm{n} \angle \mathrm{k} \angle \mathrm{y} \angle$ chí pô

nothing SM P3 neg in pot be neg

'There was nothing in the pot'

c. May pé’3 $\mathrm{k} \S \quad$ ká ywun $\angle \mathrm{z} \square$ pô

I P2 neg nobody see neg

'I saw nobody'

d. Ká ywun $\angle$ à $\quad$ pé$^{3} \mathrm{k} \S \quad$ ká ajúm yits $^{3} \quad \mathrm{z} \square \quad$ pô nobody SM P2 neg nothing some see neg

'Nobody saw anything'

e. *May pé’3 ká ywun $\angle \quad z \square$

I P2 no body see

f. *Ká ywun $\angle$ à $\quad$ pé $^{3} \quad \mathrm{z} \square \quad$ ká ajúm ${ }^{3}$ yits $^{3}$

nobody SM P2 see nothing some

All the italicized elements in (10) are refer to as negative quantifiers. Morphologically, their structure follows the description which has been provided above. For sentences like 
(10a, b, c, d) to be interpreted as negatives, the negative quantifiers must be associated and co-occur with NMs, unless the sentence is ungrammatical like (10e, f). This specificity makes Awing negative quantifiers different to that of languages like English or Dutch. Returning to preoccupation set above with consideration to (9), I provided some reasons why ká in Awing data cannot be seen as adverb like its English counterpart. Some of these ideas are that (i) ká cannot precede a sentence with subject pronoun (see 9b) with the interchangeable ${ }^{3}{ }^{\prime} \leftarrow /$ ngá does (see 8). (ii) in (9), ká is correctly used to answer a question whose content focuses on the verb object. Though the verb object is plural, pengy§ $\mathrm{p}^{3} \mathrm{p} \ddot{\mathrm{Y}} \mathrm{p}^{3}$ 'those two women' the answer uses a singular pronoun. This is legimately correct since even the English none also suits in that context. Following (i) and (ii) specific to Awing, I consider ká to be a pronounlike particle and not an adverb. Returning to negQuan, we have argued that they must be a syntactic configuration with NMS. In that configurtion, negQuan behaves like any other noun in typical negative sentence in the sense that it must be displaced to the left of the verb. Intriguing, one might wonder why, though they are many negative items in sentences like those in (10), the latter remain grammatical and interpretable. This kind of linguistic output is called negative concord. We will come back to this under sentential negation and negative concord fairly at the end of this presentation. In the same spirit let's continue with the exploration negative words also termed n-words, another subclass of NPIs.

\section{Negative words}

The concept n-word is generic notion used to qualify NPIs whose interpretation depend fundamentally on their syntactic configuration within the clause (see Muntñá 2008, Zeijlstra 2004, Laka 1990, among others). Accordingly, Giannakidou (2002:2) describes an n-word in the following: an expression $\alpha$ is an $n$-word iff (i) $\alpha$ can be used in structures containing sentential negation or another $\alpha$-expression yielding a reading equivalent to one logical negation and (ii) $\alpha$ can provide a negative fragment answer. Though the recognition of a category solely relies on its position within the sentence, this subclass of NPIs seems (at for Awing) to have as members the two previous subclasses that have been described namely negative adverbs and negative quantifiers. This intuition is based on conditions (i) and (ii) of Giannakidou's definition of n-words. Let's consider (11-12) and (9) repeated in (13):

11.

a. ywun $\angle$ yits ${ }^{3}$ a pé’3 ngî $\angle$

Person Indef SM P2 came

'Somebody came'

b. ywun $\angle \quad \mathrm{w}^{3}$ a pé ${ }^{3} \quad \mathrm{k} \S$ yî $\angle$ pô

Person Dem SM P2 neg came neg

'The person did not come'

c. May pé’3 $k \S$ ywun $\angle$ yits $^{3} \quad z \square$ pô

I P2 neg nobody Indef see neg

'I did not see anybody'

12. 
a. ká Đwun $\angle \mathrm{a}$ pé’3 $\mathrm{k} \S$ yî $\angle$ pô

nobody SM P2 neg came neg

'Nobody come'

b. ywun $\angle$ a pé’3 $\mathrm{k} \S$ yî $\angle$ pô

person SM P2 neg came neg

'Nobody come'

c. May pé’3 k§ ywun $\angle \mathrm{z} \square$ pô

I P2 neg nobody see neg

'I saw nobody'

13.

a. Pengy§ $\mathrm{p}^{3} \mathrm{p} \ddot{\mathrm{Y}} \mathrm{p}^{3} \quad$ (po) pé’3 ngì?

women two Dem SM P2 came

'Did those two women come?'

b. ká *(pó k§ yí pô)

None $*($ they did not come $)$

Relying on the definition provided above qualifying n-words, the behaviour of the PI ywun $\angle$ 'person' necessitates some clarifications. In essence $\mathrm{n}$-words are not strict negative content and ywun $\angle$ 'person' elucidates this proposal. The interpretation of ywun $\angle$ as 'somebody' or as 'nobody' in (11) and (12) depends on some conditions: (a) if ywun $\angle$ is modified by an indefinite determiner and appears in subject position in non-negative context, it is interpreted as 'somebody' (see 11a), rather if if ywun $\angle$ is modified by an indefinite determiner and appears in subject position in a strict negative context, it is interpreted as 'anybody' (see 11c).

This condition (b). (12a) is automatically negative for reasons that had been given in section 2.1.1.2. On the other hand, (c) if ywun $\angle$ stands as a bare DP (traditionally NP), it receives a negation reading regardless its argument structure as in (12b) and (12c). In opposition to $(12 \mathrm{~b} / \mathrm{c})$, if ywun $\angle$ is generated with a demonstrative like $\mathrm{w}^{3}$ and shows up in subject position, it should be rendered as 'this/that man' which seems to indicate that there is a presupposition and that ywun $\angle$ 'the person' refers to an entity that the both speaker and the listener know about. This is illustrated in (11b). In the previous section, we had argued that ká can provide a fragment negative answer and this reasoning goes in straight line with (ii) of Giannakidou'definition of n-words. Ká was described above as pronoun-like particle. It looks like the English none and the French aucun. Nevertheless, the Awing ká is more near to the French aucun than the English none for the reason that auncun can be either a determiner as in aucun enfant n'est venu 'no child came' or an indefinite pronoun as in aucun [NP enfant] n'est venu with NP-deletion. In the same spirit, ká behaves like a determiner in context where it binds nouns (see 10/11) and as a pronoun when it serves as a fragment negative answer (see 13b). Following the analysis that we have couched, it looks obvious 
many subclasses of NPIs fall under n-words. Let's continue with another issue under negation referred to as sentential negation and negative concord

\section{Sentential negation and negative concord}

Some prominent questions like one might wonder why, though they are many negative items in sentences like those in (10), the latter remain grammatical and interpretable was kept aside in previous sections. Here is a place to provide an answer to the latter. Let's keep aside this preoccupation and first indicate some concept clarifications concerning sentential negation (SN) and negative concord (NC). Typologically, the classification of languages based on negation followed from Jespersen (1917)'s publication which describes the notion of negation in English and other languages. Following Jespersen, Klima (1964) expresses a distinction between what is worth to call sentential negation $(\mathrm{SN})$ and constituent negation $(\mathrm{CN})$.

Accordingly (Klima 1964, 270-271), SN focuses on the entire sentence while CN takes in its scope a variable of the sentence. In other words, if the sentence (finite verb and its arguments) fall within the scope of a negative operator like the French ne...pas, the English not, the Dutch niet, etc., that sentence is an instance of SN. Rather, $\mathrm{CN}$ is derived if the negative operator binds a variable $\mathrm{x}$ within the sentence. Logically, $\mathrm{SN}$ has the following structure: if $X$ is true, then the negation of $X(\neg X)$ is obligatorily true. On the other hand, if $X$ is false, then $\neg X$ is necessarily true. On the other hand, Negative concord is one of the labels that have been used in the literature to describe the fact that, in some languages, negation is semantically interpreted only once even when more than one apparently negative element occurs in the sentence (see Muntñá 2008). Many examples that we have described previous fall either the domain of SN or in the domain of NC. Recalling Zeijlsta (2004) from section 1.1, SN is generated with NMs. Examples include some examples in (2) repeated below:

15.

a. Fochi a $k \S \leftrightarrow$ wa'lə ghin ${ }^{3}$ pô

Fochi SM neg school P0-go neg

'Fochi did'nt go to school'

b. Fochi a chí' $\leftrightarrow$ wa'lə $\mathrm{gh}_{i} \mathrm{n}^{3}$ pô, gho fít $\angle \mathrm{m} \angle$

Fochi SM neg school P0-go neg 2sg tell 1sg-Obj

'If Fochi did'nt go to school, tell me'

Sentential negation is marked in Awing by the presence of NMs like k§...pô in (15a) and chí'...pô in (15b). Therefore, the sentence that falls in the domain of these NMs is negative. Also note that the presence of both negative operators is mandatory for sentential negation to be realized. We have shown in previous analyses that many negative items (NMs, NPIs and n-words) can co-occur in one sentence and the interpretation of such yields only one negation in the semantics. This phenomenon has be referred to as NC. Some examples in Awing include the following where all the italicized elements are negative elements: 
16.

a. Ká ajúm ${ }^{3}$ à $\mathrm{n} \leftarrow \mathrm{k} \S \mathrm{m} \angle \mathrm{m} \mathrm{n} \angle \mathrm{k} \angle \mathrm{y} \angle$ chí pô

nothing SM P3 neg in pot be neg

'There was nothing in the pot'

b. May pé’3 $\mathrm{k} \S \quad$ ká ywun $\angle \mathrm{z} \square$ pô

I $\quad$ P2 neg nobody see neg

'I saw nobody'

c. Ká ywun $\angle$ à pé ${ }^{3} \mathrm{k} \S \quad$ ká ajúm ${ }^{3}$ yits $^{3} \quad \mathrm{z} \square$ pô

nobody SM P2 neg nothing some see neg

'Nobody saw anything'

Languages that usually exhibit NC fall in two distinct groups. The first group deals with languages in which n-words do not have the potential to solely express negation. Here, nwords must combine with NMs to generate SN. This group of languages belongs to NC subcategory called Strict Negative Concord (SNC) and includes languages like Polish, Czech, Greek (see Zeijltra 2004) and French. The second group consists of languages in which nwords have the capacity to expression negation on their own. This group is called the NonStrict Negative Concord (NSNC) and it includes languages like Spanish, Italian, Catalan and English, among others. In conclusion, alone, n-words in Awing cannot express negation. Therefore, Awing belongs to the SNC group. In the last section, I will focus on negative imperatives.

\section{Negative imperatives}

Languages also differ following how they express negative imperatives. Typologically, some languages are said be true negative imperative through the imperative mood while others use the subjunctive or the indicative mood to mark the same reality, commands or bans. The first group includes languages like French and English with true negative imperatives like ne sors pas! don't go out! respectively. The second group includes languages like Italian and Spanish which do not have this capacity. Instead, they use surrogate imperative expressed by the subjunctive mood (Zanuttini 1997, 1998, 2001, Haegeman 1995, among others). In addition to the existing two groups, there is a third group which seems to have both true negative and surrogate imperatives. This last group includes languages like Dutch (see Zeijlsta 2004). What is the position of Awing with respect to what precedes? Awing does have negative imperative constructions (see Nyomy 2019):

17. [true negative imperative]

a. $\mathrm{K}^{\mathrm{TM}} \mathrm{f} \wedge \mathrm{l} \angle \mathrm{p} i \leftrightarrow^{3}$ !

NIMgo out

'Do not go out!'

b. $\mathrm{K}^{\mathrm{TM}} \mathrm{gh}^{\prime \prime} \mathrm{n}^{3} \mathrm{~m}^{3}$ teen ${ }^{3}$ ! 
NIM go market

'Do not go the market!'

Awing has the true negative imperative constructions that are used to indicate bans. These structures are preceded by the negative marker (NIM) $\mathrm{k}^{\mathrm{TM}}$ which always shows up sentence initially. Contrasting with other negative constructions like sentential negation where negation is syntactically expresses by a bipartite marker, negative imperatives are realized with a single negative operator that scopes over the whole clause as in (17). (17) expresses a ban with all the imperative force that it might have for the reason that the command is giving directly to the addressee. The interpretation will be softer or polite in constructions in which the command is directly giving to the executor like in (17):

18.

a. $\mathrm{K}^{\mathrm{TM}}$ Fochi $\mathrm{f} \wedge \mathrm{l} \angle \mathrm{p} \dot{\leftrightarrow} \leftrightarrow{ }^{3}$ !

NIMFochi go out

'Fochi should not go out!'

b. $\mathrm{K}^{\mathrm{TM}}$ Fochi $\mathrm{gh}^{\prime \prime} \mathrm{n}^{3} \mathrm{~m}^{3} \mathrm{teen}^{3}$ !

NIM Fochi go market

'Fochi should not go the market!'

It appears that in (18) by contrast to (17), instructions are not given directly to the concerned beneficiary but to an intermediate whose role is to make sure that Fochi executes the instructions. Based on in this interpretation (18) looks more subjunctive that imperative as in (17). Imperatives are generally said to be agentless, that is the instructor (the grammatical subject) is absence in the sentence. Nevertheless, the entity to whom the command is given may be overtly present in the utterance. Consider (19):

19.

a. $\quad \mathrm{f} \wedge \mathrm{l}^{3}$ pí $\leftrightarrow^{3 !}$

go out

'(You) go out!'

b. $\mathrm{f} \wedge \mathrm{d}-\mathrm{n} \angle \mathrm{p} i \leftrightarrow 3$ !

go-2Pl out

sort-ez dehors

'Go out!'

c. $\mathrm{k} \prod 1^{3} \quad \mathrm{ng} \angle \mathrm{sá} \leftrightarrow{ }^{3}$ !

eat maize

'Eat maize!'

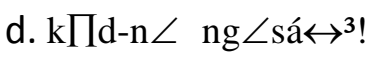

eat-2Pl maize 
mang-ez maïs

'eat maize!'

20.

a. $* \mathrm{~K}^{\mathrm{TM}}$ f $\wedge \mathrm{d}-\mathrm{n} \angle \mathrm{p} i \leftrightarrow 3 !$

NIM go-2Pl out

NIM sort-ez dehors

'Go out!'

b. $* \mathrm{~K}^{\mathrm{TM}} \mathrm{k} \prod \mathrm{d}-\mathrm{n} \angle \mathrm{ng} \angle \mathrm{sá} \leftrightarrow{ }^{3}$ !

NIM eat-2Pl maize

NIM mang-ez maïs

'Eat maize!'

Before commenting (19) and (20), I want to say to recall that Awing does not have the sort of inflection that French has. I mean that the language lacks overt person morphology which usually distinguish 1,2 and 3sg or 1,2 and 3Pl as the French language does have the 1sg |e|, the $2 \mathrm{sg}|\mathrm{es}|$, the $3 \mathrm{sg}|\mathrm{e}|$, the $1 \mathrm{pl}|\mathrm{ons}|$, the $2 \mathrm{pl}|\mathrm{ez}|$ and $3 \mathrm{pl}|\mathrm{ent}|$ in the present tense. In the imperative, some of these person declinations clearly distinguish the addressee. However, Awing has only two SM that stand for 3sg (a) and 3Pl (po). But these person markers are not of any use in the imperative because they cannot be interpreted as related to person but instead as pronouns. Nonetheless, data have brought evidence that Awing has a $2 \mathrm{pl} \mathrm{clitic.} \mathrm{Comparing}$ (19a) to (19b), the first illustration does not have an overt person marker while in the second, there appears at the verb rightmost position a 2 pl person clitic marker materialized as $|-\mathrm{n} \angle|$. The same holds in (19c) and (19d). Intriguing is that the $2 \mathrm{pl}$ clitic person only shows up in positive imperative and is ungrammatical in negative imperative as (20) demonstrates. Now, the question is why (19b-d) is acceptable and not (20)? Though interesting as question might be, it goes beyond the scope of this paper, therefore I allow the question open. But (20) is acceptable if the person clitic is replaced with the corresponding pronoun. Consider (21):

21.

a. $\left.\mathrm{K}^{\mathrm{TM}} \quad \mathrm{p}\right\lrcorner \quad \mathrm{f} \wedge 1 \angle \mathrm{p} i \leftrightarrow \leftrightarrow^{3 !}$

NIMPrn.2pl go out

'Do not go out!' ('Ne sortEZ pas')

b. $\left.\mathrm{K}^{\mathrm{TM}} \quad \mathrm{p}\right\lrcorner \mathrm{k} \prod \mathrm{l} \angle \mathrm{ng} \angle \mathrm{sá} \leftrightarrow{ }^{3}$ !

NIMPrn.2pl eat maize

'Do not eat maize!' ('Ne mangEZ pas du maïs')

c. $\mathrm{K}^{\mathrm{TM}} \quad \mathrm{p}_{i} \mathrm{n} \angle \quad \mathrm{k} \prod \mathrm{l} \angle \mathrm{ng} \angle \mathrm{sá} \leftrightarrow 3$ !

NIMPrn.1pl eat maize

'Do not eat maize!' ('Ne mangeONS pas du maïs') 


\section{d. $\mathrm{K}^{\mathrm{TM}} \quad(\mathrm{O}) \quad \mathrm{k} \prod \mathrm{l} \angle \mathrm{ng} \angle \mathrm{sá} \leftrightarrow \leftrightarrow^{3}$ !}

NIMPrn.2sg eat maize

'Do not eat maize !' ('Ne mangES pas du maïs')

Though (21) is correct and stands to be typical instantiations of negative imperatives, one would have expected the interpretation to follow that of (18) if it is assumed that pronouns replace nouns. But is not the case for the reason the pronouns in (21) do not really stand there as subjects but rather as default person marking which bear the features as the French capitalized person features |-EZ| in (21a-b), |-ONS| in (21c) and the |-ES| in (21d). Though the imperative mood holds for the pronouns listed above, it odes not to work with all pronouns. There is not strict imperative reading with the following pronouns in (22):

22.

a. $\mathrm{K}^{\mathrm{TM}} \quad \mathrm{ma} \leftrightarrow \quad \mathrm{fil} \angle \mathrm{pi} \leftrightarrow{ }^{3}$

NIMPrn.1sggoout

'That I should not go out' ('Que je ne sorte pas')

c. $\mathrm{K}^{\mathrm{TM}}$ á $\mathrm{fil} \angle \mathrm{pí \leftrightarrow} \leftrightarrow^{3}$

NIM Prn.3sg go out

'That s/he should not go out' ('Qu'il ne sorte pas')

f. $\mathrm{K}^{\mathrm{TM}} \quad$ pó $\quad \mathrm{f}_{\mathrm{i}} \mathrm{l} \angle \quad$ pí $\leftrightarrow^{3}$

NIM Prn.3pl go out

'That they should not go out' ('Qu'ils ne sortent pas')

The reading in (22) is that of subjunctives. Some reasons can explain this state of affairs. In addition to explanation provided for (18), the pronouns in (22) do not function like default person declination, but as nominal substitutes. If the pronouns in (22) are replaced by Fochi the same reading as in (18) will still hold because in this particular situation, the pronoun and the noun have the same characteristics. We can therefore conclude that (i) if the instruction is given directly to its executor, (the construction is imperative but (ii) if the command is not given directly to the executor or is given to the latter through an intermediate, the sentence is subjunctive. However, (22a) seems to raise some reserves regarding (i) and (ii). The problem with (22a) is that one cannot receive an order from oneself. Therefore (22a) is typically a subjunctive. Keep in mind that the subjunctive provided above is solely based on the interpretation given to the latter with respect to the type of ban that is derived. In words, those sentences are not intrinsically strict subjunctive in the sense of the subjunctive mood. Beside this interpretation, the language has strict subjunctive constructions (see Nyomy 2019). The aim of this section was to find out whether Awing has or not true negative imperatives. I have provided evidence that true negative imperatives are available in the said language and that in addition to the latter, Awing also displays surrogate imperative. Following these analyses, I conclude that Awing belongs to the third group alongside Dutch, a group of languages that has both true negative imperatives and surrogate imperative. 


\section{Conclusion}

This paper has addressed the expression of negation in Awing. I have discussed the issue with respect to negative markers, negative polarity items and n-words. The language has various NMs that are used to express sentential negation. I have shown that the reading related to $\mathrm{n}$ words depends on the ways the n-words are combined. Talking about NPIs, I have argued that the interpretation of the negative adverb la' $\leftarrow$ is typically related to context sensitivity since it can either the read as 'ever' in positive context or as 'never' in negative sensitive environment. It had also been demonstrated that the negQuan ká is pronoun-like particle in the sense of the French aucun and the English none. Dealing with sentential negation, the explanation is that in Awing, negative words and NPIs must co-occur with NMs to express $\mathrm{SN}$. In that sequence, they (all negative items) enter into NC relation. In other terms, the occurrence of these multiple negative elements generate only one negation at the logical form. Following this line of reasoning, Awing belongs to Strict Negative Concord language. Despite that the fact that interpretation plays an important role, true negative imperatives are available in Awing.

\section{References}

[1] BELL, A. and WASIKE. A. (2004). 'Negation in Bukusu'. Paper presented at the 35th Annual Conference on African Linguistics. Boston. MA.

[2] CORBLIN, F. and TOVENA, L. (2003). 'L'expression de la négation dans les langues romanes'. In D. Godard, (Ed.). Les langues romanes : problèmes de la phrase simple. Pp 279-342. Paris: CNRS Editions.

[3] GIANNAKIDOU, A. (1997). The landscape of Polarity Items. Ph.D. thesis. Rijks Universiteit, Groningen.

[4] GIANNAKIDOU, A. (1999). 'Affective dependencies'. Linguistics \& Philosophy 22. Pp 367-421.

[5] GIANNAKIDOU, A. (2002). N-words and Negative Concord. Ms. University of Chicago.

[6] HAEGEMAN, L. (1995). The syntax of negation. Cambridge: Cambridge University Press.

[7] JESPERSEN, O. (1917). Negation in English and other Languages. Copenhagen: A.F. Høst.

[8] KLIMA, E. S. (1964). 'Negation in English'. In: J. A. Fodor \& J.J. Katz (Eds.). The structure of Language: Readings in the philosophy of language. Pp 246-323. Englewood Cliffs, NJ: PrenticaHall, Inc.

[9] LAKA, I. (1990). Negation in Syntax: on the Nature of Functional Categories and Projections. $\mathrm{Ph} . \mathrm{D}$. thesis, MIT.

[10] MUNTAÑÁ, S. T. (2008). Negative Concord in English and Romance: Syntax-Morphology Interface Conditions on the Expression of Negation. Ph.D. thesis, Universitat Autònoma de Barcelona

[11] NYOMY, C. (2019). Negation, Remnant Movement and Clause Structure in Awing. Ph.D. dissertation, the University of Yaounde I.

[12] ZANUTTINI, R. (1998). Negation and clausal structure. A Comparative Study of Romance languages. Oxford studies in comparative syntax. New York, Oxford: Oxford University Press.

[13] ZANUTTINI, R. (2001). 'Sentential Negation.' In BALTIN \& COLLINS (Eds). The Handbook of Contemporary Syntactic Theory. Pp 511-535. London: Blackwell.

[14] ZANUTTTINI, R. (1997b). Negation and clausal structure. A comparative study of Romance languages. Oxford: Oxford University Press.

[15] ZEIJLSTRA, H. (2004). Sentential Negation and Negative Concord, Ph.D. thesis, University of Amsterdam. 